\title{
Faktor Yang Berhubungan Dengan Keikutsertaan I bu Hamil Dalam Kelas Ibu Hamil
}

\author{
Desmariyenti ${ }^{*}$, Susi $\mathrm{H}$ artati \\ A kademi Kebidanan Sempena N egeri Pekanbaru \\ *email: riyen.desmariyenti@gmail.com
}

\begin{abstract}
Pregnant women class is a learning facility for pregnant women in undergoing the process of pregnancy and postpartum. Based on the preliminary survey conducted by researchers in the work area of Payung Sekaki Primary Health Center, it was obtained data that the narration of midwives working in the work area of Payung Sekaki Primary Health Center was indeed carried out, but there were still many pregnant women who had not utilized maternal facilities optimally. The purpose of this study is the Factors Associated with the Participation of Pregnant Women in the Work Area Payung Sekaki Primary Health Center 2018. This type of research is quantitative using correlation analysis with Chi-square. The population in the study amounted to 297 people, with a total sample of 75 people with accidental sampling technique. This research was carried out in the work area of Payung Sekaki Primary Health Center Pekanbaru on 05 to 28 July 2018. The results showed that there was a relationship between knowledge and maternal participation in the class of pregnant women in the work area of Payung Sekaki Primary Health Center with a $p$-value $=0,000$, there was a relationship between parity with the participation of pregnant women in the Working A rea of Payung Sekaki Primary Health Center with a $p$-value $=0.025$ and there is a relationship of family support with the participation of pregnant women in the work area of Payung Sekaki Primary Health Center with a $p$-value $=0.03$ with a degree of Error $\alpha=0,1$

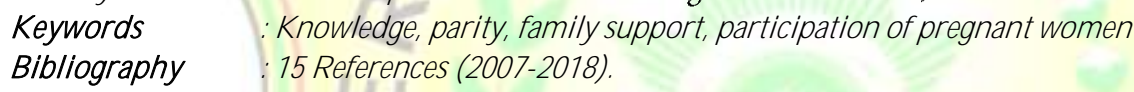

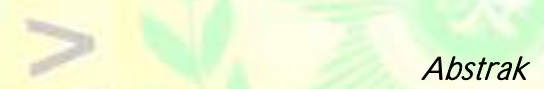

Kelas ibu hamil merupakan sarana belajar bagi ibu hamil dalam menjalani proses kehamilan dan pasca melahirkan. Berdasarkan Survey awal yang dilakukan oleh peneliti di wilayah kerja Puskesmas Payung sekaki, diperoleh data bahwa penuturan bidan yang bekerja di wilayah kerja puskesmas Payung Sekaki memang pelaksanaan kelas ibu hamil telah terlaksana, namun tetapi masih banyak ibu hamil yang belum memanfaatkan fasilitas kelas ibu hamil secara optimal. Tujuan penelitian ini adalah Faktor yang Berhubungan dengan Keikutsertaan Kelas I bu Hamil di wilayah kerja Puskesmas Payung Sekaki Tahun 2018.Jenis penelitian ini adalah kuantitatif menggunakan analisis korelasi dengan Chi-square. Populasi dalam penelitian berjumlah 297 orang, dengan jumlah sampel 75 orang dengan teknik accidental sampling.Penelitian ini di laksanakan di wilayah kerja puskesmas Payung Sekaki Pekanbaru tanggal 05 sampai 28 juli 2018. Hasil penelitian didapatkan ada hubungan antara pengetahuan dengan keikutsertaan ibu dalam kelas ibu hamil di Wilayah Kerja Puskesmas Payung Sekaki dengan nilai $p$-value $=0,000$, ada hubungan hubungan antara paritas dengan keikutsertaan kelas ibu hamil di Wilayah Kerja Puskesmas Payung Sekaki dengan nilai $p$-value =0,025 dan ada hubungan dukungan keluarga dengan keikutsertaan kelas ibu hamil di Wilayah Kerja Puskesmas Payung Sekaki dengan nilai p-value $=0,03$ dengan derajat Kesalahan $\alpha=0,1$.

Katakunci : : Pengetahuan, paritas, dukungan keluarga, keikutsertaan kelas ibu hamil

Daftar pustaka $\quad$ : 15 Referensi (tahun 2007-2018).

\section{PENDAHULUAN}

Angka Kematian Ibu (AKI) merupakan salah satu indikator untuk mengukur derajat kesehatan perempuan.Tingkat kematian ibu merupakan masalah kesehatan yang menarik perhatian World Health Organization (WHO). Fakta menunjukan lebih dari 350.000 di seluruh dunia meninggal setiap tahun akibat 
komplikasi kehamilan dan persalinan. Pada tahun 2016 menyatakan bahwa Indonesia merupakan salah satu Negara penyumbang AKI terbesar di dunia dan di Asia Tenggara (W H O, 2017).

Menurut Survey Demografi dan Kesehatan Indonesia (SDKI) mengungkapkan bahwa jumlah kasus kematian ibu saat melahirkan turun dari 4.999 kasus pada 2015 menjadi 4.912 kasus di tahun 2016. Sementara hingga semester satu di tahun 2017 terjadi 1.712 kasus kematian ibu saat proses persalinan (SD KI, 2017). Kehamilan menurut (W iknjosastro, 2009) mendefinisikan kehamilan sebagai suatu proses yang terjadi antara perpaduan sel sperma dan ovum sehingga terjadi konsepsi sampai lahirnya janin, lamanya hamil normal adalah 280 hari atau 40 minggu dihitung dari H aid Pertama Haid Terakhir (HPHT).

Wanita hamil dianjurkan melakukan olahraga ringan selama hamil agar ibu dan janin lebih sehat dan berkurangnya masalah-masalah yang timbul pada kehamilannnya. Salah satu olahraga ringan yang dapat dilakukan ibu hamil ialah senam hamil. Bila dicermati lebih lanjut, sebenarnya dalam gerakan senam hamil terkandung efek relaksasi yang bermanfaat menstabilkan kecemasan dan mengurangi rasa takut dengan cara relaksasi fisik dan mental, serta mendapatkan informasi yang mempersiapkan mereka untuk mengalami apa yang akan terjadi selama persalinan dan kelahiran (Wibowo, Arief dan Larasati, 2012). Kelas ibu hamil diharapkan dapat meningkatkan pengetahuan, merubah sikap dan perilaku ibu agar memahami tentang kehamilan, perubahan tubuh dan keluhan selama kehamilan, perawatan kehamilan, persalinan, perawatan nifas, keluarga berencana pasca persalinan, penyakit menular dan akte kelahiran (Depkes RI, 2016). Pelaksana kelas ibu hamil umumnya, Bidan dalam hal ini mempunyai tugas sebagai fasilitator dalam program kelas ibu hamil, yang dalam pelaksanaan kelas ibu hamil yang dapat meminta bantuan nara sumber untuk menyampaikan materi bidang tertentu (Depkes RI, 2016).

Berdasarkan data dinas kesehatan Kota Pekanbaru dari bulan Oktober - November tahun 2017 angka kehamilan ibu sekitar 4447 orang. Jumlah ibu hamil tertinggi di dapat di Wilayah kerja Puskesmas Payung Sekaki sebesar 442 orang.D ata terakhir pada bulan Desember 2017 terdapat 297 ibu hamil.Puskesmas Payung Sekaki merupakan salah satu puskesmas di Kota Pekanbaru yang telah melaksanakan program kegiatan kelas ibu hamil di wilayahnya.Menurut penuturan bidan di wilayah kerja Puskesmas Payung Sekaki, bahwa pelaksanaan kelas ibu hamil memang telah dijalankan.Akan tetapi masih banyak ibu hamil di wilayah kerja Puskesmas Payung Sekaki yang belum memanfaatkan fasilitas kelas ibu hamil ini secara optimal. Kelas ibu hamil merupakan suatu kegiatan belajar kelompok bagi ibu hamil dalam bentuk tatap muka yang bertujuan untuk meningkatkan pengetahuan dan ketarampilan ibu-ibu mengenai kehamilan, perawatan kehamilan, persalinan, perawatan nifas, perawatan bayi baru lahir, mitos, penyakit, dan akta kelahiran. Di dalam kelas ibu hamil akan menciptakan interaksi, diskusi dan pertukaran pengalaman antara ibu hamil dengan ibu hamil dan antara ibu hamil dengan petugas kesehatan/ bidan mengenai Kesehatan Ibu dan Anak (KIA) (Kemenkes RI, 2016).

Menurut (Notoatmodjo, 2007), perilaku merupakan suatu respon atau reaksi seseorang terhadap stimulus (rangsangan dari luar). Perilaku terjadi melalui proses adanya stimulus terhadap organisme, dan kemudian 
organisme tersebut merespons. M eskipun perilaku adalah bentuk respon atau reaksi terhadap stimulus atau rangsangan dari luar organisme (orang), namun dalam memberikan respon sangat tergantung pada karakteristik atau faktor lain dari orang yang besangkutan. $\mathrm{Hal}$ ini berarti meskipun stimulusnya sama bagi beberapa orang, namun respon tiap-tiap orang berbeda. Pengetahuan dapat diartikan sebagai hasil dari "Tahu" yang terjadi setelah orang melakukan penginderaan terhadap suatu objek tertentu. Penginderaan terjadi melalui panca indra manusia, yaitu: indra penglihatan, pendengaran, penciuman, rasa dan raba. Sebagian besar pengetahuan manusia diperoleh melalui mata dan telinga (N otoatmodjo, 2007).

Menurut penelitian yang dilakukan oleh (Desmariyenti; Sarlis, Nelfi; Fitriani, 2018) dan penelitian yang dilakukan oleh (Hartati, 2018) dengan menggunakan uji statistik Chi Square didapatkan hasil bahwa pengetahuan dapat memberikan dampak terhadap ibu hamil dalam mengikuti suatu kegiatan. Artinya pengetahuan sangat mempengaruhi seseorang dalam melakukan tindakan terutama dalam mengikuti kelas ibu hamil. Paritas merupakan jumlah anak yang dilahirkan baik lahir hidup maupun meninggal. Paritas lebih dari empat kali mempunyai resiko yang lebih besar untuk terjadi perdarahan, demikian dengan ibu yang terlalu sering hamil menyebabkan resiko untuk sakit, kematian dan juga anaknya (Depkes RI, 2016). Keluarga adalah unit masyarakat terkecil. Oleh karena itu, untuk mencapai perilaku masyarakat yang sehat harus dimulai di masing-masing keluarga.Di dalam keluarga mulai terbentuk perilaku-perilaku masyarakat. Keluarga juga merupakan pemicu seseorang untuk berbuat sesuatu (N otoatmodjo, 2010).

Lingkungan keluarga merupakan lingkungan yang sangat berpengaruh terhadap keberhasilan kelas ibu hamil. Keluarga (suami, orang tua, mertua, ipar dan sebagainya) perlu diinformasikan bahwa seorang ibu perlu dukungan dan bantuan keluarga agar melaksanakan kelas ibu hamil.Bagian keluarga yang mempunyai pengaruh yang paling besar terhadap keikutsertaan kelas ibu hamil adalah suami.M asih banyak suami yang berpendapat salah, yang menganggap kelas ibu hamil adalah tidak perlu. Peranan suami akan turut menentukan keinginan ibu hamil dalam mengikuti kelas ibu hamil guna untuk menambah wawasan dalam menjaga keadaan emosi atau perasaan ibu (Roesli, 2008).

\section{METODE PENELITIAN}

Jenis penelitian ini adalah kuantitatif menggunakan analisis korelasi. Desain yang dipakai dalam penelitian ini adalah observasi analitik dengan pendekatan cross sectional. Populasi yang digunakan dalam penelitian ini adalah ibu hamil yang berada di wilayah kerja Puskesmas Payung Sekaki Tahun 2018 yaitu sebanyak 297 orang ibu hamil dengan jumlah sampel sebanyak 75 orang.

\section{HASIL DAN PEMBAHASAN}

Berdasarkan data yang telah dikumpulkan dari Wilayah Kerja Puskesmas Payung Sekaki Pekanbaru pada tanggal 05 - 28 Juli 2018. 


\section{Analisis Unvariat}

1. Pengetahuan ibu hamil tentang kelas ibu hamil

Tabel 1

Frekuensi Pengetahuan Ibu Hamil tentang Kelas I bu

\begin{tabular}{cccc}
\hline No & Pengetahuan & Frekuensi & $\begin{array}{c}\text { Persentase } \\
(\%)\end{array}$ \\
\hline 1 & Baik & 24 & $32.00 \%$ \\
2 & Cukup & 29 & $38.67 \%$ \\
3 & Kurang & 22 & $29.33 \%$ \\
\hline & Total & 75 & $100 \%$ \\
\hline
\end{tabular}

Terdapat pengetahuan ibu hamil mayoritas dalam pengetahuan cukup sebanyak 29 orang (38,67\%) dan minoritas pengetahuan kurang sebanyak 22 orang $(29,33 \%)$.

2. Paritas ibu hamil

Tabel 2

Frekuensi Paritas Ibu Hamil

\begin{tabular}{|cccc|}
\hline No & Paritas & Frekuensi & $\begin{array}{c}\text { Persentase } \\
(\%)\end{array}$ \\
\hline 1 & Primipara & 17 & $22.67 \%$ \\
2 & Multipara & 49 & $65.33 \%$ \\
3 & Grande & 9 & $12.00 \%$ \\
\hline & Multipara & 75 & $100 \%$ \\
\hline
\end{tabular}

Paritas ibu hamil mayoritas dalam kategori multipara sebanyak 49 orang $(65,33 \%)$ dan minoritas kategori grande multipara sebanyak 9 orang (12\%).

3. Dukungan keluarga ibu hamil

Tabel 3

Frekuensi Dukungan Keluarga I bu Hamil

\begin{tabular}{|c|c|c|c|}
\hline No & Dukungan keluarga & Frekuensi & Persentase (\%) \\
\hline 1 & Tidak M endukung & 14 & $18.67 \%$ \\
\hline 2 & M endukung & 61 & $81.33 \%$ \\
\hline & Total & \multicolumn{2}{|r|}{$100 \%$} \\
\hline
\end{tabular}

Mayoritas terdapat dukungan keluarga ibu hamil dalam kategori mendukung sebanyak 61 orang $(81,33 \%)$ dan minoritas kategori tidak mendukung sebanyak 14 orang (18,67\%).

4. Keikutsertaan ibu hamil dalam kelas ibu hamil

Tabel 4

Frekuensi Keikutsertaan Ibu H amil Dalam Kelas Ibu H amil

\begin{tabular}{cccc}
\hline No & Kelas I bu hamil & Frekuensi & Persentase (\%) \\
\hline 1 & Tidak M engikuti & 22 & $29.33 \%$ \\
2 & M engikuti & 53 & $70.67 \%$ \\
\hline & Total & 75 & $100 \%$ \\
\hline
\end{tabular}

Mayoritas kategori mengikuti sebanyak 53 orang $(70,67 \%)$ dan minoritas keikutsertaan kelas ibu hamil dalam kategori tidak mengikuti sebanyak 22 orang (29,33\%). 


\section{Analisis Bivariat}

1. Hubungan Pengetahuan dengan Keikutsertaan Kelas I bu Hamil

Tabel 5

H ubungan Pengetahuan dengan Keikutsertaan Kelas I bu Hamil

\begin{tabular}{|c|c|c|c|c|c|c|c|c|c|}
\hline \multirow{2}{*}{ No } & \multirow{2}{*}{ Pengetahuan } & \multicolumn{4}{|c|}{ Kelas Ibu hamil } & \multicolumn{2}{|c|}{ Total } & \multirow{2}{*}{$\begin{array}{c}P \\
\text { value }\end{array}$} & \multirow[b]{2}{*}{$a$} \\
\hline & & Tidak M engikuti & $\%$ & M engikuti & $\%$ & $\mathrm{~F}$ & $\%$ & & \\
\hline 1 & Baik & 2 & 8.33 & 22 & 91.67 & 24 & 32.00 & \multirow{4}{*}{.000} & \multirow{4}{*}{0.1} \\
\hline 2 & Cukup & 5 & 13.51 & 24 & 64.86 & 29 & 38.67 & & \\
\hline 3 & Kurang & 15 & 68.18 & 7 & 31.82 & 22 & 29.33 & & \\
\hline & Total & 22 & 29,33 & 53 & 70,64 & 75 & 100 & & \\
\hline
\end{tabular}

Pengetahuan ibu yang baik dan tidak mengikuti kelas ibu hamil sebanyak 2 orang $(8,33 \%)$ dan ibu yang mengikuti kelas ibu hamil sebanyak 22 orang $(91,67 \%)$. Sedangkan ibu berpengetahuan cukup yang yang tidak mengikuti kelas ibu hamil sebanyak 5 orang $(13,51 \%)$ dan ibu yang mengikuti kelas ibu hamil sebanyak 24 orang (64,86\%), dan ibu berpengetahuan kurang tidak mengikuti kelas ibu hamil sebanyak 15 orang $(68,18 \%)$ dan ibu yang mengikuti kelas ibu hamil sebanyak 7 orang (31,82\%). Dari hasil uji Chi-Square dengan menggunakan sistem komputerisasi menunjukkan hasil dengan $\mathrm{p}$ - value $=0,000$.

2. Hubungan Paritas dengan Keikutsertaan Kelas I bu Hamil

Tabel 6

Hubungan Paritas dengan Keikutsertaan Kelas I bu Hamil

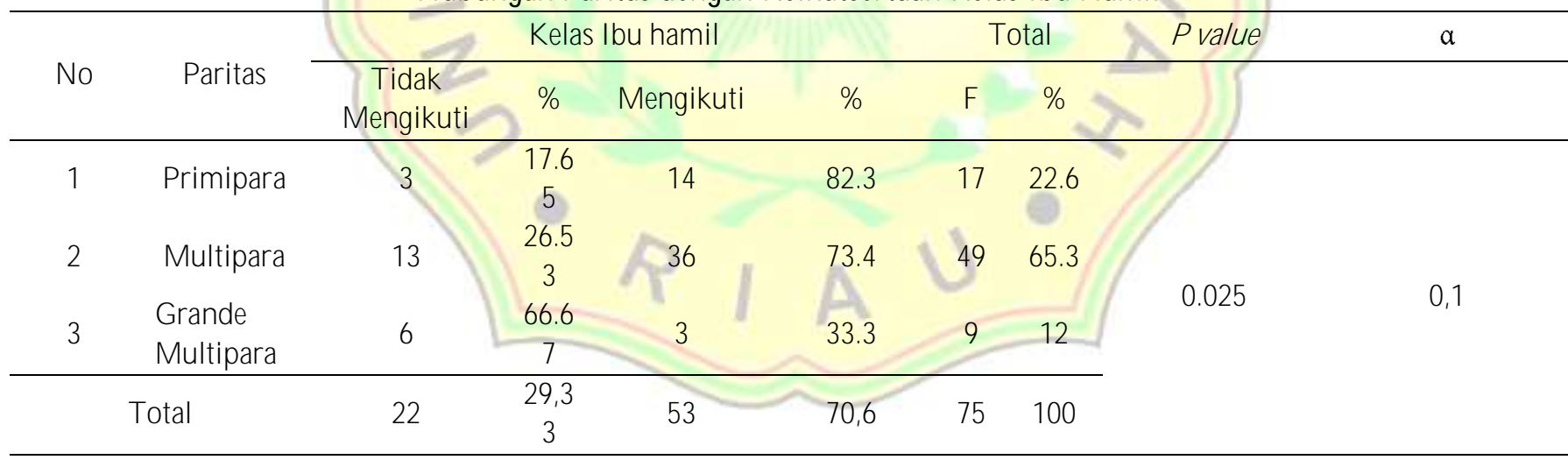

Paritas ibu dengan kategori primipara yang tidak mengikuti kelas ibu hamil sebanyak 3 orang $(17,65 \%)$ dan ibu memiliki paritas kategori primipara mengikuti kelas ibu hamil sebanyak 14 orang $(82,35 \%)$. Sedangkan ibu dengan paritas kategori multipara yang tidak mengikuti kelas ibu hamil sebanyak 13 orang (26,53\%) dan ibu dengan kategori paritas multipara yang mengikuti kelas ibu hamil sebanyak 36 orang $(73,46 \%)$, dan ibu kategori paritas grande multipara yang tidak mengikuti kelas ibu hamil sebanyak 6 orang $(66,67 \%)$ dan ibu dengan kategori grande multipara mengikuti kelas ibu hamil sebanyak 3 orang (33,33\%). Dari hasil uji Chi-Square dengan menggunakan sistem komputerisasi menunjukkan hasil dengan $p$ - value=0,025. 
3. Hubungan dukungan keluarga dengan keikutsertaan kelas ibu hamil

Tabel 7

Hubungan Dukungan Keluarga dengan Keikutsertaan Kelas I bu H amil

\begin{tabular}{|c|c|c|c|c|c|c|c|c|c|}
\hline \multirow[b]{2}{*}{ No } & \multirow{2}{*}{$\begin{array}{c}\text { Dukungan } \\
\text { keluarga }\end{array}$} & \multicolumn{4}{|c|}{ Kelas Ibu hamil } & \multicolumn{2}{|c|}{ Total } & \multirow[t]{2}{*}{ P Value } & \multirow[t]{2}{*}{$a$} \\
\hline & & $\begin{array}{c}\text { Tidak } \\
\text { M engikuti }\end{array}$ & $\%$ & M engikuti & $\%$ & $\mathrm{~F}$ & $\%$ & & \\
\hline 1 & $\begin{array}{c}\text { Tidak } \\
\text { M endukung }\end{array}$ & 9 & 64.2 & 5 & 35.7 & 14 & 18.67 & \multirow{3}{*}{0.003} & \multirow{3}{*}{0,1} \\
\hline 2 & Mendukung & 13 & 21.3 & 48 & 78.6 & 61 & 81.33 & & \\
\hline & Total & 22 & 29,4 & 53 & 70,6 & 75 & 100 & & \\
\hline
\end{tabular}

Dukungan dengan kategori tidak mendukung yang tidak mengikuti kelas ibu hamil sebanyak 9 orang (64,29\%) dan dukungan keluarga tidak mendukung yang mengikuti kelas ibu hamil sebanyak 5 orang (35,71\%). Sedangkan dukungan keluarga dengan kategori mendukung yang tidak mengikuti kelas ibu hamil sebanyak 13 orang $(21,31 \%)$ dan dukungan keluarga kategori mendukung yang mengikuti kelas ibu hamil sebanyak 48 orang (78,69\%). Dari hasil uji Chi-Square dengan menggunakan sistem komputerisasi menunjukkan hasil dengan $\mathrm{p}$ value $=0,003$

\section{SIM PULAN}

Dari hasil uji Chi-Square diperoleh hasil dengan nilai $p$-value $=0,000$ dan derajat kesalahan $a=0,1$ menunjukkan bahwa ada hubungan yang bermakna antara pengetahuan dengan keikutsertaan kelas ibu hamil di wilayah kerja Puskesmas Payung Sekaki Pekanbaru Tahun 2018. Pengetahuan ibu hamil dalam mengikuti kelas ibu hamil memberikan dampak yang jelas kepada ibu hamil dalam mengikuti kelas ibu hamil.

a. Analisis Bivariat H ubungan Pengetahuan dengan Keikutsertaan Kelas I bu H amil

M enurut (Notoatmodjo, 2010) yang menyebutkan bahwa Pengetahuan adalah hasil pengindraan manusia, atau hasil tahu seseorang terhadap objek melalui indra yang dimilikinya (mata, hidung, telinga, dsb). Dengan adanya pengetahuan ini tentunya ibu hamil mampu mengetahui tujuan diadakannya kelas ibu hamil pada waktu kehamilan.Dengan adanya pengetahuan peningkatan pengetahuan pada ibu hamil tentang kelas ibu hamil maka semakin banyak ibu yang mengikuti kelas ibu hamil.

Penelitian ini sejalan dengan penelitian yang dilakukan oleh (Hidayah, Nurul; M uhaimin, 2018) dengan Faktor yang Mempengaruhi Pemanfaatan Kelas Ibu Hamil mengungkapkan bahwa terdapat hubungan yang signifikan antara pengetahuan dengan pemanfaatan kelas ibu hamil dengan nilai $p$ value 0,000 . Hal ini membuktikan bahwa semakin tinggi kualitas pengetahuan ibu hamil, maka pemahaman tentang pentingnya mengikuti kelas ibu hamil akan semakin dirasakan oleh ibu hamil. Berdasarkan hasil penelitian yang dilakukan peneliti, maka dapat diasumsikan bahwa pengetahuan ibu hamil dapat memberikan peningkatan terhadap keikutsertaan ibu hamil dalam mengikuti kelas ibu hamil yang dilakukan oleh puskesmas. Keikutsertaan ini 
dapat menambah wawasan ibu hamil dalam mempersiapkan persalinan.Dalam hal ini pengetahuan memberikan peran penting bagi ibu hamil untuk meningkatkan kegiatan kelas ibu hamil. Namun dari 75 orang ibu hamil masih terdapat 2 orang ibu hamil yang memliki pengetahuan baik tidak mengikuti kelas ibu hamil, hal ini terjadi akibat paritas ibu hamil yang tergolong grande multipara dan ibu berpengetahuan rendah mengikuti kelas ibu hamil terdapat 7 orang, hal ini disebabkan oleh adanya dukungan keluarga yang baik dalam memberikan motivasi kepada ibu hamil untuk mengikuti kelas ibu hamil. Sedangkan ibu yang memiliki pengetahuan baik terdapat 2 (dua) orang yang tidak mengikuti kelas ibu hamil, hal ini disebabkan oleh paritas ibu, ibu dengan paritas grande multipara akan cenderung tidak memiliki waktu yang banyak untuk mengikuti kelas ibu hamil karena banyak menghabiskan waktu bersama keluarga, dan ibu grande multipara sudah merasa berpengalaman dalam menghadapi proses persalinan.

b. Analisis Bivariat H ubungan Paritas dengan Keikutsertaan Kelas I bu H amil

Dari hasil uji Chi-Square diperoleh hasil dengan nilai $p$-value $=0,025$ dan derajat kesalahan $a=0,1$ menunjukkan bahwa ada hubungan yang bermakna antara paritas dengan keikutsertaan kelas ibu hamil di wilayah kerja Puskesmas Payung Sekaki Pekanbaru Tahun 2018. paritas ibu hamil dalam mengikuti kelas ibu hamil meberikan dampak yang jelas kepada ibu hamil dalam mengikuti kelas ibu hamil. Paritas merupakan faktor resiko komplikasi obstetric maka ibu hamil dengan paritas tinggi cenderung mengalai plsenta previa sehingga pertumbuhan endometrium kurang sempurna (Wiknjosastro, 2009). I bu yang baru pertama kali hamil merupakan hal yang sangat baru sehingga termotivasi dalam peningkatan kesehatan kehamilannya, sebaliknya ibu yang sudah pernah melahirkan lebih dari satu beranggapan lebih berpengalaman dalam melahirkan, namun mereka cenderung mengikuti untuk menambah kesiapan pasca melahirkan (Wiknjosastro, 2009)

Penelitian ini sejalan dengan yang dilakukan oleh (Impartina, 2017) dengan judul hubungan paritas dengan partisipasi mengikuti senam hamil didapatkan hasil nilai $p$ value 0,000 , artinya ada hubungan antara paritas ibu dengan keikutsertaan senam hamil. Dapat disimpulkan bahwa ibu hamil yang memiliki paritas atau jumlah anak yag banyak akan mempengaruhi keikutsertaan ibu hamil dalam mengikuti kelas ibu hamil ataupun senam hamil. Berdasarkan penelitian yang teah dilakukan dapat diasumsikan bahwa paritas ibu hamil memberikan hubungan yang signifikan terhadap keikutsertaan ibu dalam mengikuti kelas ibu hamil. Keikutsertaan ibu hamil dalam kelas ibu hamil diketahui mampu memberikan peningkatan pengetahuan ibu hamil dalam merawat kehamilan, menyambut kelahiran bayi dan memberikan pengetahuan terhadap ibu pasca melahirkan. Namun dilihat dari data yang diperoleh masih terdapat ibu primipara yang tidak mengikuti kelas ibu hamil sebanyak 3 orang $(17,65 \%)$, hal ini disebabkan karena ibu primipara memiliki pengetahuan yang rendah tentang kelas ibu hamil. Sedangkan ibu dengan paritas grande multipara terdapat 3 orang $(33,33 \%)$ yang mengikuti kelas ibu hamil, keikutsertaan ibu grande multipara disebabkan oleh adanya dukungan keluarga yang baik untuk memotivasi ibu agar mengikuti kelasibu hamil.

c. Analisis Bivariat H ubungan Dukungan Keluarga dengan Keikutsertaan K elas I bu H amil

Dari hasil uji Chi-Square diperoleh hasil dengan nilai $p$-value $=0,003$ dan derajat kesalahan $a=0,1$ menunjukkan bahwa ada hubungan yang bermakna antara dukungan keluarga dengan keikutsertaan kelas 
ibu hamil di wilayah kerja Puskesmas Payung Sekaki Pekanbaru Tahun 2018. Dukungan keluarga pada ibu hamil dalam mengikuti kelas ibu hamil meberikan dampak yang jelas kepada ibu hamil dalam mengikuti kelas ibu hamil.

Hasil penelitian ini sejalan dengan penelitian yang dilakukan oleh (Astuti, Widi Wulan; Sofiyanti, Ida; Widyaningsih, 2016) dengan judul faktor-faktor yang berhubungan dengan keikutsertaan mengikuti kelas ibu hamil di puskesmas Candrito Kabupaten Temanggung. Hasil uji statistik didapatkan nilai $p=0,033$ menunjukkan bahwa terdapat hubungan yang signifikan antara dukungan keluarga dengan keikutsertaan kelas ibu hamil. Berdasarkan hasil penelitian dapat diasumsikan bahwa dukungan keluarga dapat memberikan dampak yang signifikan terhadap keikutsertaan kelas ibu hamil. Dukungan keluarga dapat dengan mudah memberikan dampak yang nyata bagi perkembangan keikutsertaan ibu hamil dalam mengikuti kelas ibu hamil. Sehingga dengan demikian semakin besar dukungan yang diberikan oleh keluarga kepada ibu hamil untuk memotivasi dalam mengikuti kelas ibu hamil, maka semakin besar tingkat keikutsertaan ibu dalam mengikuti kelas ibu hamil. $N$ amun dengan demikian masih terdapat keluarga yang mendukung tidak mengikuti kelas ibu hamil sebanyak 13 orang, hal ini disebabkan oleh masih kurangnya pengetahuan ibu tentang mengikuti kelas ibu hamil dan keluarga yang tidak mendukung terdapat mengikuti kelas ibu hamil sebanyak 5 orang, kejadian ini disebabkan oleh adanya pengetahuan ibu yang baik, sehingga ibu memiliki keinginan yang kuat untuk datang mengikuti kelas ibu hamil.

\section{KESIM PULAN}

Dari hasil penelitian dapat disimpulkam bahwa dari hasil uji Chi Squareterdapat hubungan antara pengetahuan dengan nilai $P$-value $=0,000$, paritas dengan nilai $P$-value $=0,025$ dan dukungan keluarga dengan nilai $P$-value $=$ 0,003 dengan keikutsertaan ibu hamil dalam kelas ibu hamil.

\section{DAFTAR PUSTAKA}

Astuti, Widi Wulan; Sofiyanti, Ida; Widyaningsih, A. (2016). Faktor-faktor/yang Berhubungan dengan Keikutsertaan M engikuti kelas Ibu Hamil Di Puskesmas Candiroto Kabupaten Temanggung. RAKERNAS AIPKEMA. Retrieved from https://jurnal.unimus.ac.id/index.php/psn12012010/article/view/2068/2096

Desmariyenti; Sarlis, N elfi; Fitriani, R. (2018). H ubungan Pengetahuan dan Sikap I bu Dengan Keputusan Waktu

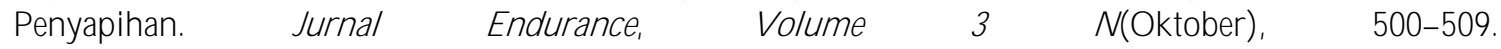
https://doi.org/http://doi.org/10.22216/jen.v3i3.3141

Hartati, S. (2018). Hubungan Pengetahuan Ibu Primigravida Tentang Tanda Bahaya Kehamilan dengan Kunjungan Antenatal Care Terintegrasi di Wilayah Kerja Puskesmas Harapan Raya Pekanbaru Tahun 2017. Menara I/mu, XII No. 1aOktober), 175-181. Retrieved from https://jurnal.umsb.ac.id/index.php/menarailmu/article/view/1037/882

Hidayah, Nurul; Muhaimin, T. N. (2018). Faktor Yang M empengaruhi pemanfaatan Kelas Ibu Hamil Tahun 2018. Photon, 9 No. 1(Oktober), 76-88. Retrieved from http://ejurnal.umri.ac.id/index.php/photon/article/view/1060/615 
Impartina, A. (2017). Hubungan Paritas dengan Partisipasi Ibu Hamil M engikuti Senam Hamil. Surya, Volume og(Agustus), 44-48.

Mahdiyah., D. (2017). Hubungan Pengetahuan Dengan Sikap Ibu Hamil Tentang Kelas Ibu Hamil Di Desa Kertak Hanyar Ii Wilayah Puskesmas Kertak Hanyar Kabupaten Banjar Tahun 2016. AKBID Sari Mulia Banjarmasin.

Notoatmodjo, S. (2007). Promosi Kesehatan Dan I/mu Perilaku. Jakarta: Rineka Cipta.

Notoatmodjo, S. (2010). Promosi Kesehatan Dan I/mu Perilaku. Jakarta: Rineka Cipta.

RI, D. (2016). Manajemen Laktasi. Jakarta: Dirjen Pelayanan M edic.

RI, K. (2016). Profil Kesehatan Indonesia. Jakarta: Kemenkes RI.

Roesli, U. (2008). Manajemen pelayanan kebidanan. Jakarta: Pustaka Bunda.

SDKI. (2017). Survey Demografi dan Kesehatan Indonesia.

WH O. (2017). W orld H ealth Organization (WHO).

Wibowo, Arief dan Larasati, I. P. (2012). Pengaruh Keikutsertaan Senam Hamil Terhadap Kecemasan Primigravida Trimester Ketiga dalam M enghadapi Persalinan. Universitas Airlangga.

Wiknjosastro, H. (2009). I/mu Kebidanan. Jakarta: Yayasan Bina Pustaka Sarwono Prawirohardjo.

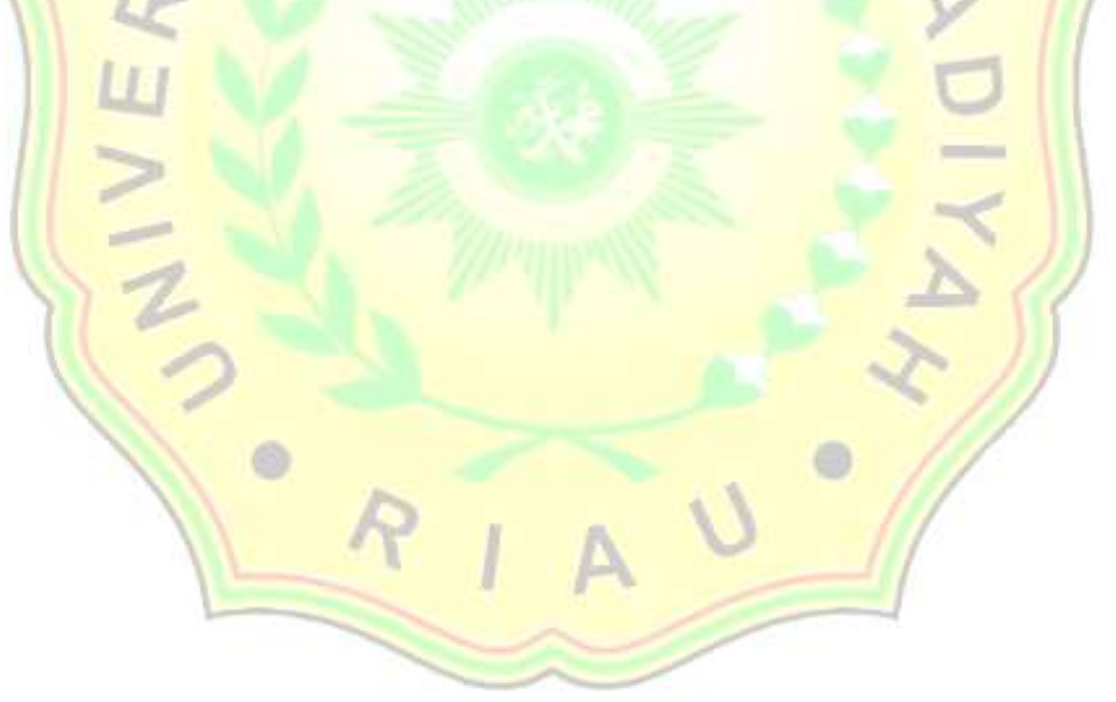

